\title{
Ruínas e Memórias de Cuba: Leituras de Reinaldo Arenas e Pedro Juan Gutiérrez a Partir dos Ecos da Revolução
}

\author{
José Veranildo Lopes da Costa Junior ${ }^{I}$ \\ Thays Keylla de Albuquerque ${ }^{I I}$
}

Resumo: A literatura latino-americana contemporânea está marcada pela ocorrência de projetos memorialísticos que, dentre outros desdobramentos, revisitam o passado, a partir das escritas de si. Este artigo analisa, brevemente, dois autores cubanos: Reinaldo Arenas, com a obra Antes que anoiteça (1992), e Pedro Juan Gutierréz com Trilogia Suja de Havana (1998). O objetivo é refletir sobre como a literatura narra as ruínas e as memórias do regime de Fidel Castro, no contexto da década de 1990, e como cada um desses autores reconstrói esse período histórico a partir de memórias individuais e coletivas.

Palavras-chave: Literatura cubana. Reinaldo Arenas. Pedro Juan Gutiérrez.

\section{Ruins and memories of Cuba: interpretations of Reinaldo Arenas and Pedro Juan Gutiérrez from echoes of the rebolution}

\begin{abstract}
Contemporary Latin American literature is marked by memorialistic projects that, among other unfoldings, revisit the past, from personal, autobiographical, autoficcional accounts. This essay analyzes two Cuban authors: Reinaldo Arenas, with his book Before Night Falls (1992), and Pedro Juan Gutierréz, with Dirty Havana Trilogy (1998). It aims at reflecting on how literature narrates the debris and memories of Fidel Castro's regime in the context of the 1990s, and on how each of these authors reconstructs this historical period from individual and collective memories.
\end{abstract}

Keywords: Cuban literature. Reinaldo Arenas. Pedro Juan Gutiérrez.

Artigo recebido em 15/10/2019 e aprovado em 27/11/2019. 


\section{RUÍNAS E MEMÓRIAS DE CUBA: LEITURAS DE REINALDO ARENAS E PEDRO JUAN GUTIÉRREZ A PARTIR DOS ECOS DA REVOLUÇÃO \\ JOSÉ VERANILDO LOPES DA COSTA JUNIOR \\ THAYS KEYLLA DE ALBUQUERQUE}

\section{Introdução}

Quando consideramos os cruzamentos entre história e ficção, notamos que a maior parte das narrativas contadas, seja numa perspectiva historiográfica seja numa perspectiva da ficção, debruça-se sobre uma versão da história: a dos vencedores. A tradição está cheia de narrativas sobre vitórias, normalmente, que representam, na perspectiva ocidental, protagonistas masculinos, brancos, burgueses, colonizadores ou detentores do poder. Apesar de saber que existem iniciativas que demonstram a perspectiva dos vencidos, como nos mostra a obra de León de Portilla, Visión de los vencidos: relaciones indígenas de la Conquista ${ }^{\mathrm{III}}$, de fato, ainda são minoritárias as narrativas que exploram ângulos e protagonistas não-hegemônicos.

Por isso, não seria exagero dizer que a crítica literária, ou pelo menos um setor mais conservador dela, pouco se ocupou, até os dias atuais, do debate sobre outras versões da história, sobre as narrativas que a história oficial se nega a contar até os nossos dias, que fazem parte de uma política de esquecimento, tema que Elizabeth Jelin explica detalhadamente no livro Los Trabajos de la Memoria ${ }^{I V}$. Nesse sentido, para contrapor o discurso hegemônico, o filósofo francês Paul Ricœur ${ }^{\mathrm{V}}$ advoga que todos nós possuímos um dever de memória com o passado, sobretudo, no concernente aos traumas coletivos que ocorrem em comunidades nacionais. Este compromisso de memória tem sido reivindicado, nos Estudos Literários, principalmente pelo viés do contemporâneo, cujo compromisso do pesquisador do tempo presente é também ético, na construção de trabalhos de memória, considerando temporalidades da memória que se enquadram no amplo espectro dos estudos sobre memória. Refletir sobre o passado de Cuba, as visões sobre os ecos da Revolução Cubana, compreende uma série de memórias subjetivas que também se metamoforseiam no decorrer do tempo, de acordo com as demandas de cada contexto cultural e sócio-político que volta a olhar para o tema respondendo a velhas e/ ou novas questões. Torna-se necessário, portanto, compreender, algumas premissas básicas no trabalho com memória:

\footnotetext{
Primero, entender las memorias como procesos subjetivos, anclados en experiencias y en marcas simbólicas y materiales. Segundo, reconocer a las memorias como objeto de disputas, conflictos y luchas, lo cual apunta a prestar atención al rol activo y productor de sentido de los participantes en esas luchas, enmarcados en relaciones de poder. Tercero, <historizar $>$ las memorias, o sea, reconocer que existen cambios históricos en el sentido del pasado, así como en el lugar asignado a las memorias en diferentes sociedades, climas culturales, espacios de luchas políticas e ideológicas ${ }^{\mathrm{VI}}$.
}

Nesse sentido, sabemos como se configura de forma única a questão da Revolução Cubana no contexto latino-americano, como foi (e ainda é) uma inspiração para o movimento de esquerda no nosso continente e como representa, até hoje, uma vitória contra os mecanismos de opressão capitalistas, e metonimicamente estadunidenses. No entanto, há uma disputa permanente com diferentes trabalhos de memória (e esquecimento) que também negam uma narrativa positiva sobre a Revolução e os acontecimentos que se sucederam a ela e reverberam na vida da população de Cuba até a atualidade. Acreditamos no pluralismo de perspectivas, mas entendemos que nenhuma postura é neutra e, por isso, torna-se cada vez mais 


\section{RUÍNAS E MEMÓRIAS DE CUBA: LEITURAS DE REINALDO ARENAS E PEDRO JUAN GUTIÉRREZ A PARTIR DOS ECOS DA REVOLUÇÃO \\ JOSÉ VERANILDO LOPES DA COSTA JUNIOR \\ THAYS KEYLLA DE ALBUQUERQUE}

imprescindível a ocupação do espaço de voz e da construção da história por sujeitos sociais que não detém a posição de poder. Assim, defendemos a emergência de ler e reler a história da América Latina para construir também outras narrativas, que permitam esquadrinhar perspectivas periféricas, que colocam luz sobre outros personagens e vivências. Desse modo, estamos de acordo com a ideia de que uma característica basilar do nosso continente é o autoritarismo. Há, em nossas memórias, diversos e recorrentes períodos em que o autoritarismo constituiu uma política de Estado - cujo pêndulo político oscila entre governos de direita, mas também de esquerda.

Como desdobramento desse ponto de vista, a literatura contemporânea latinoamericana apresenta muitos autores com projetos memorialísticos preocupados em construir memórias sobre o passado recente, revisitando momentos traumáticos marcados pelo autoritarismo. Há, assim, uma efervescência de escritas do eu, de narradores da experiência que buscam retratar, algumas vezes, com personagens protagonistas homônimos, situações individuais que apontam para perspectivas coletivas, para contextos históricos específicos relacionados às comunidades nacionais.

Levando em conta o exposto, este artigo reflete sobre a literatura cubana a partir de dois autores e obras da década de 90: Reinaldo Arenas, escritor exilado pelo governo de Fidel Castro, com a obra Antes que anoiteça ${ }^{V I I}$, e Pedro Juan Gutierréz com Trilogia Suja de Havana ${ }^{\text {VIII }}$. Esses escritores dialogam com outros autores e autoras da América Latina que também discutem o contexto sócio-histórico de seus países, tais como: Pedro Lemebel (Tengo miedo torero), Alejandro Zambra (Formas de volver a la casa), Nona Fernández (La dimensión desconocida), no Chile; Bernardo Kucinsky ( $K$; Você vai voltar pra mim; Os visitantes), Marcelo Rubens Paiva (Ainda estou aqui), Maria Valéria Rezende (Outros Cantos), no Brasil; Laura Alcoba (La casa de los conejos), Félix Bruzzone, (Los Topos), Marta Dillon, (Aparecida), na Argentina.

Dessa forma, todas as obras citadas anteriormente e, de modo específico, os dois textos que serão analisados em nosso artigo, de Reinaldo Arenas e Pedro Juan Gutiérrez, têm em comum um mesmo traço: eles funcionam como retratos de contextos autoritários das sociedades latino-americanas, exemplificando questões de cunho sociohistórico e, sobretudo, político. Destacamos, contudo, que enquanto Arenas cultiva mais o cunho autobiográfico, Gutiérrez busca uma vertente autoficcional, ou seja, de acordo com Manuel Alberca, em El pacto ambíguo: de la novela autobiográfica a la autoficción ${ }^{\mathrm{IX}}$, as diferentes escritas do eu podem ser lidas a partir de três caminhos: do pacto autobiográfico (pretenso compromisso com dados referenciais objetivos); do pacto ficcional (não há compromisso com a realidade objetiva ou com a verossimilhança); do pacto ambíguo, marcado pela dúvida nos limites entre o autobiográfico e o ficcional, um pacto autoficcional, (mantém a ambiguidade sobre o que na obra faz referência a fatos objetivos e o que é pura ficção).

Neste espaço, no entanto, nosso objetivo principal não se delineia na exploração e discussão sobre gêneros e vertentes do literário, senão em perceber como os dois romancistas cubanos narram o cotidiano de Cuba durante o regime de Fidel Castro e como essas obras são significativas para continuarmos as discussões sobre as memórias 


\section{RUÍNAS E MEMÓRIAS DE CUBA: LEITURAS DE REINALDO ARENAS E PEDRO JUAN GUTIÉRREZ A PARTIR DOS ECOS DA REVOLUÇÃO JOSÉ VERANILDO LOPES DA COSTA JUNIOR THAYS KEYLLA DE ALBUQUERQUE}

da revolução cubana, sobre seus desdobramentos durante a crise dos anos 1990 e sobre seus ecos também no presente e no futuro da América Latina.

Para realizar a análise proposta, este texto encontra-se dividido em duas seções. $\mathrm{Na}$ primeira, examinamos a obra de Reinaldo Arenas a partir de três momentos particulares nos quais a obra do romancista cubano aborda e problematiza questões de gênero e sexualidade. Na segunda seção, realizamos uma leitura da obra de Pedro Juan Gutiérrez a partir de apreciações sobre memória e espaço em Cuba, também atravessadas pela experiência do sexo. Em comum, percebemos que as duas obras narram um deterioro moral e espacial. Em Arenas há uma deterioração do comportamento, que aparece relacionada à iniciação sexual e aos ritos de passagem - a partir da zoofilia, por exemplo. Em Pedro Juan Gutiérrez, a degradação do espaço urbano está presente na vivência do cotidiano, como se observa na presença do mau cheiro e das ruínas que tomam as ruas, as casas e as personagens de Trilogia Suja de Havana.

\section{Homossexualidade e memórias em Cuba na autobiografia Antes que Anoiteça, de Reinaldo Arenas}

No Brasil, a crítica literária contemporânea tem se ocupado em discutir a visão de grupos minoritários (LGBT, mulheres, negros, favelados, indígenas) sobre eventos históricos. Atualmente, presenciamos um boom de romances recém-publicados e, consequentemente, de pesquisas que se voltam, por exemplo, para o golpe de Estado de 1964. Este movimento de revisitar o passado através da literatura é também exercitado em outros países (e em outras literaturas), como no caso das ditaduras argentina, chilena e paraguaia. Entretanto, quando pensamos no contexto da revolução cubana, pouco se discute sobre outra versão da história: a vida (de personagens marginais) durante o regime de Fidel Castro.

Nesta linha, é preciso fazer um adendo. Não estamos dizendo que o regime cubano não tenha sido tema de estudos. Pelo contrário, notamos um acentuado número de pesquisas em torno dessa temática, nas mais diversas áreas do saber, como a Literatura, a História, a Política, a Sociologia, a Antropologia, etc. Contudo, pouca atenção tem sido dada à reconstrução do regime de Fidel Castro através do olhar dos sujeitos que compõem o tecido social desprestigiado, como a perspectiva das mulheres, dos homossexuais e dos artistas - que foram, em muitos casos, expulsos de Cuba, sendo obrigados a viver o exílio na Europa e nos Estados Unidos, principalmente.

Uma dessas histórias é a de Reinaldo Arenas, um escritor assumidamente homossexual, nascido em Holguín em 1943, e falecido nos Estados Unidos em 1990. Arenas dedicou-se à Poesia e ao Teatro, tendo estudado na Faculdade de Letras da Universidade de Havana. Escreveu, durante anos, a sua autobiografia intitulada Antes que anoiteça ${ }^{X}$, a qual foi traduzida em vários idiomas e se transformou em filme, estrelado pelo ator espanhol Javier Bardem. 


\section{RUÍNAS E MEMÓRIAS DE CUBA: LEITURAS DE REINALDO ARENAS E PEDRO JUAN GUTIÉRREZ A PARTIR DOS ECOS DA REVOLUÇÃO \\ JOSÉ VERANILDO LOPES DA COSTA JUNIOR \\ THAYS KEYLLA DE ALBUQUERQUE}

Quando analisamos o enredo do livro, notamos que muitos são os temas tratados na história narrada por Reinaldo Arenas, alguns se sobressaem, por exemplo: a fome, a miséria, a iniciação sexual de garotos, as perseguições políticas durante o regime de Fidel Castro, a AIDS, o exílio e a morte. O texto começa com uma reflexão sobre a vida na ilha, "ou se vive conforme se deseja, ou é melhor acabar com a vida. Em Cuba, eu tinha suportado inúmeros sofrimentos, pois a esperança de fuga e a possibilidade de salvar meus manuscritos sempre me deram um grande estímulo"XI. Essa citação anuncia o modo discursivo no qual a narrativa será construída: utilizando a conjunção ou o narrador inicia um jogo de dualidades - ou se vive livre em Cuba ou a morte (ou o exílio) torna-se o destino.

Não obstante, uma temática importante na vida de Reinaldo Arenas é a experiência sexual, que pode ser entendida como uma espécie de revolução ao conservadorismo imposto por Fidel Castro. Nessa mesma linha de raciocínio, Cabrera Infante chegou a descrever Reinaldo Arenas com as seguintes palavras: "Três paixões regem a vida de Reinaldo Arenas: a literatura [...], o sexo passivo e a atividade política. Das três, a mais dominante foi, sem dúvidas, o sexo". Ao concordar com a descrição de Cabrera Infante, notamos que a narrativa sobre o sexo na autobiografia Antes que anoiteça pode ser dividida em três momentos importantes: o primeiro diz respeito a um período de descoberta do sexo durante a juventude; o segundo a uma vivência homossexual como um mecanismo de resistência; o terceiro corresponde a uma revolução sexual em Cuba. Passemos, agora, a analisar três excertos que ilustram os momentos citados anteriormente, na autobiografia de Reinaldo Arenas:

\footnotetext{
Naquele período, minhas relações sexuais se deram com bichos. Primeiro, as galinhas, as cabras, as porcas. Depois, quando fui ficando um pouco mais velho, as éguas; transar com uma égua representava um ato geralmente coletivo. Todos os garotos subiam numa pedra para alcançar a altura do animal e curtiam aquele prazer; tratava-se de um buraco quente e, para todos nós, infinito ${ }^{\mathrm{XII}}$.
}

Na narrativa de Arenas percebemos que o sexo ganha fundamental importância e chega a ilustrar o cotidiano da sua vida em Cuba. A sexualidade é experimentada de inúmeras maneiras. Temos a masturbação que ocorre quando o protagonista, por exemplo, vai nadar em um rio com outros jovens pelados. O sexo propriamente dito acontece com a prima Dulce Ofélia. Também se conta sobre o desejo sexual entre o narrador e os garotos da escola. Além disso, a experiência sexual com animais aparece como algo constante. Nesse sentido, a simbologia do ato sexual com uma égua implica considerar o meio rural no qual Arenas estava imerso. Naquele contexto, parece que o sexo com animais representava, tacitamente, um teste da masculinidade para aqueles garotos que iniciavam suas vidas sexuais conhecendo "o infinito". Por outro lado, podese pensar também nessa prática como uma tentativa de extrapolar as fronteiras do conhecido, do si mesmo, uma tentativa de diluir-se no desconhecido.

O segundo momento, aquele que diz respeito à homossexualidade como um mecanismo de resistência, mostra que o regime de Fidel Castro foi extremamente intolerante com os homossexuais, como podemos ver a seguir:

Eu era um adolescente trancado num acampamento com mais de dois mil jovens, proibidos de sair à rua. Seria possível pensar - eu mesmo penso assim 


\title{
RUÍNAS E MEMÓRIAS DE CUBA: LEITURAS DE REINALDO ARENAS E PEDRO JUAN GUTIÉRREZ A PARTIR DOS ECOS DA REVOLUÇÃO \\ JOSÉ VERANILDO LOPES DA COSTA JUNIOR \\ THAYS KEYLLA DE ALBUQUERQUE
}

- que aquele período era o mais apropriado para que eu desenvolvesse as minhas tendências homossexuais e tivesse inúmeras relações eróticas; não tive nenhuma. Sofria então de todos os males típicos de uma sociedade machista, exaltados pela revolução; naquela escola marcada por uma virilidade militante, não parecia haver espaço para o homossexualismo que, já nesse período, era severamente punido, chegando inclusive a dar cadeia. No entanto, entre aqueles jovens praticou-se, com certeza, o homossexualismo, embora de forma bastante velada. Os rapazes que eram apanhados em pleno ato tinham que desfilar com suas camas e todos os pertences até o almoxarifado, onde, por ordem da direção, deviam devolver tudo; os outros colegas tinham que sair dos alojamentos para apedrejá-los e enchê-los de socos. Era uma expulsão sinistra, pois existia um documento que iria perseguir aquele jovem durante toda a vida e impedi-lo de estudar em outra escola do Estado - o Estado já estava começando a exercer um controle sobre absolutamente tudo. Muitos dentre aqueles jovens que passavam com suas camas nas costas pareciam viris. Ao ver aquele espetáculo, eu me sentia envergonhado e aterrorizado. "Entendido, é isso que você é", eu voltava a ouvir a voz do meu colega de turma na escola secundária, e percebia que "ser entendido", em Cuba, representava uma das maiores desgraças que podem acontecer a um ser humano ${ }^{\mathrm{XIII}}$.

Uma das críticas ao regime de Fidel Castro faz menção ao desrespeito em relação às sexualidades não-hegemônicas. Nesse sentido, o que a Literatura de Reinaldo Arenas nos mostra é um forte aparelho de repressão aos homossexuais. O discurso do governo legitimou uma série de práticas preconceituosas a comunidade gay naquele período. No relato do escritor cubano, três elementos chamam atenção. Primeiramente temos o caráter machista da Revolução. Depois, aparece a premissa de que, possivelmente, os combatentes praticavam a homossexualidade entre si, mesmo que de forma velada. Por último, a vida do homossexual se transformava, nessa conjuntura política, em uma "desgraça". Em entrevista realizada em 2010, ao jornal mexicano $L a$ Jornada, Fidel Castro chegou a afirmar que: "Soy el responsable de la persecución a homosexuales que hubo en Cuba". Mesmo considerando uma onda conservadora, a homossexualidade vivida no âmbito da vida pública, por jovens como Arenas, por exemplo, se transformou em uma forma de resistência à postura heteronormativa excludente celebrada por Fidel Castro. Em resposta a esta onda conservadora, chegamos ao terceiro momento que gostaríamos de comentar: uma revolução sexual em Cuba. Nas palavras de Reinaldo Arenas:

\begin{abstract}
Acho que a revolução sexual em Cuba foi realmente um produto da repressão existente. Talvez como um protesto contra o regime, as práticas homossexuais começaram a proliferar, cada vez mais. Por outro lado, como a ditadura era considerada um mal, tudo que ela havia condenado era interpretado como uma atitude positiva pelos dissidentes, que nos anos 1960 representavam a maioria. Acredito, francamente, que os campos de concentração para homossexuais e os policiais disfarçados de rapazes obsequiosos, para encontrar e prender os homossexuais, trouxeram apenas como resultado um maior desenvolvimento da atividade homossexual ${ }^{\mathrm{XIV}}$.
\end{abstract}

Ao longo da narrativa, Arenas traz diversas práticas de perseguição aos homossexuais implementadas pelo governo de Fidel Castro, dentre elas, cita as leis e os campos de concentração homossexual. Contudo, o que se pode notar é que este aparelho de repressão, ao provocar a organização social e política da comunidade gay cubana, gerou uma revolução sexual que tinha como objetivo disseminar, na ilha, a liberdade do 


\section{RUÍNAS E MEMÓRIAS DE CUBA: LEITURAS DE REINALDO ARENAS E PEDRO JUAN GUTIÉRREZ A PARTIR DOS ECOS DA REVOLUÇÃO \\ JOSÉ VERANILDO LOPES DA COSTA JUNIOR \\ THAYS KEYLLA DE ALBUQUERQUE}

corpo e dos desejos. Com isso, construiu-se uma resposta a Fidel Castro, à opressão do Estado.

$\mathrm{O}$ retrato de Cuba feito por Reinaldo Arenas associa a vivência do sexo com a experiência política. Nesse sentido, o escritor se utiliza das suas memórias individuais, bem como de eventos do cotidiano, para construir uma narrativa maior, que coloca Fidel Castro como um líder autoritário. Esta narrativa nos parece importante porque questiona a gênese da Revolução Cubana: buscava-se, naquele momento, a construção de uma sociedade igualitária. Contudo, temos aí um paradoxo ético: esta sociedade igualitária condenou a homossexualidade e perseguiu os cidadãos que se identificavam com outras formas de sexualidade, aproximando-se de um Estado autoritário. O livro de Arenas configura-se, então, como um objeto da recordação ${ }^{\mathrm{XV}}$ que permite a aproximação a uma memória individual, que alude a uma coletividade homossexual, não hegemônica, a obra pode ser considerada um trabalho de memória ${ }^{\mathrm{XVI}}$ no concernente à construção de uma visão crítica sobre o Estado cubano, nesse caso marcado pela violência da opressão e da perseguição a determinado perfil social na Cuba do governo revolucionário.

\section{Ruínas e memórias de Cuba na Trilogia Suja de Havana, de Pedro Juan Gutiérrez}

No concernente a Pedro Juan Gutierréz e o livro Trilogia Suja de Havana ${ }^{X V I}$, principal obra do escritor, pode-se pensar a memória a partir da autoficção hispanoamericana, na relação do eu com o grupo sócio-cultural ao que pertence. Na obra, evidencia-se como o presente está atravessado por memórias, como alguns espaços territoriais têm marcações explícitas que demonstram conexões entre diferentes épocas e vivências. $\mathrm{O}$ autor explora os ecos do passado que cruzam e delineiam o cotidiano da Cuba da década de 90, com o foco na capital, Havana. O mau cheiro, a fome, a cidade que desmorona são características constantes nesses relatos, que se desenvolvem em uma perspectiva autoficcional, bruta e desencantada. Propomos aqui algumas considerações sobre como as memórias pessoais de Pedro Juan, narrador-personagem protagonista do livro, refletem sobre Havana como corpo territorial simbólico, um espaço que expõe a situação coletiva de Cuba.

$\mathrm{Na}$ esfera dos estudos sobre as escritas de si (escritas do eu), fala-se bastante sobre as fronteiras e mesclas entre realidade e ficção, além da ênfase dada em estarmos vivendo na literatura contemporânea um momento de retorno do autor, da perspectiva subjetiva e da exposição da intimidade. No entanto, quando pensamos sobre a autoficção, sobre textos que já carregam como proposta a hibridização de gêneros, a interligação produtiva literariamente entre referencialidade e imaginação criativa, observamos narrativas que se configuram para além de exercícios egoliterários, de pura exposição da intimidade. Assim, como destaca Leonor Arfuch sobre os gêneros das escritas do eu, em $O$ espaço biográfico: dilemas da subjetividade contemporânea:

Seria possível afirmar, então, que efetivamente, e para além de todos os jogos de simulação possíveis, esses gêneros, cujas narrativas são atribuídas a personagens realmente existentes, não são iguais; que, inclusive, mesmo quando estiver em jogo uma certa "referencialidade", enquanto adequação 


\title{
RUÍNAS E MEMÓRIAS DE CUBA: LEITURAS DE REINALDO ARENAS E PEDRO JUAN GUTIÉRREZ A PARTIR DOS ECOS DA REVOLUÇÃO JOSÉ VERANILDO LOPES DA COSTA JUNIOR THAYS KEYLLA DE ALBUQUERQUE
}

aos acontecimentos de uma vida, não é isso o que mais importa. Avançando uma hipótese, não é tanto o conteúdo do relato por si mesmo - a coleção de acontecimentos, momentos, atitudes -, mas precisamente as estratégias ficcionais - de autorrepresentação o que importa. Não tanto a "verdade" do ocorrido, mas sua construção narrativa, os modos de (se) nomear no relato, o vaivém da vivência ou da lembrança, o ponto do olhar, o que se deixa na sombra; em última instância, que história (qual delas) alguém conta de si mesmo ou de outro eu. E é essa qualidade autorreflexiva, esse caminho da narração, que será, afinal de contas, significante ${ }^{\mathrm{XVIII}}$.

Nesse sentido, nos interessa os textos que pressupõem a fíccionalização da realidade, e ao mesmo tempo em que falam de si, falam também do outro, da situação político-social em que os narradores estão imersos. Essa é a localização da obra de Pedro Juan Gutierréz, que em entrevista ao jornal espanhol El Cultural, em 2001, afirma que: "narro coisas reais que aconteceram comigo ou com os meus vizinhos. A matéria prima brota apenas ao me aproximar da varanda e olhar o que me rodeia". Essa é a ideia da narrativa de Pedro Juan, que utiliza sua biografia, a memória, a observação etnográfica e o cenário de Havana para elaborar sua literatura.

Essas considerações sobre autoficção referentes ao contexto sociopolítico nos fazem lembrar das considerações do filósofo francês Jacques Rancière, tanto em $A$ partilha do sensivel ${ }^{X I X}$ quanto em $A$ revolução estética ${ }^{X X}$, quando comenta sobre os desdobramentos da relação entre arte e vida, política e estética, e constrói uma linha de raciocínio que interliga essas esferas:

\begin{abstract}
No regime estético da arte, a arte é arte na medida em que é algo além de arte. É sempre "estetizada", o que quer dizer que é sempre colocada como uma "forma de vida". A fórmula-chave do regime estético da arte é que a arte é uma forma autônoma de vida. Essa é uma fórmula, no entanto, que pode ser lida de duas maneiras diferentes: a autonomia pode ser enfatizada em detrimento da vida ou a vida em detrimento da autonomia - e essas linhas de interpretação podem ser opostas ou podem se cruzar. Essas oposições e intersecções podem ser registradas como a interação entre três grandes cenários. Arte pode se tornar vida. Vida pode se tornar arte. Arte e vida podem trocar suas propriedades. ${ }^{\mathrm{XI}}$
\end{abstract}

$\mathrm{Na}$ autoficção de Pedro Juan, vida e literatura se misturam, e é na ambigüidade entre realidade e ficção que se concretiza o artifício de sua narrativa. Deste modo, no livro composto por três livros, por isso Trilogia, esse conjunto de relatos que podem ser considerados contos ou um romance, narra as desventuras de Pedro Juan durante a crise econômica da década de 90, no contexto da dissolução da União Soviética, com fome, sexo, violências, drogas, imundície e mau cheiro. A situação social de desemprego, alcoolismo, prostituição, imigração, suicídio e privação de liberdades individuais também está enfocada, tudo isso no cenário de Havana como espaço metonímico de Cuba.

Em muitos momentos do livro, Havana aparece como um lugar em ruínas, podre, onde tudo está prestes a cair e cheira mal. As moradias de Pedro Juan em diferentes cortiços da cidade aparecem repetidamente em descrições detalhadas e reflexões sobre a vida nesses ambientes. No conto Ancorado na terra de ninguém, o narrador fala sobre o edifício que vive e acaba de passar por um desmoronamento: 


\section{RUÍNAS E MEMÓRIAS DE CUBA: LEITURAS DE REINALDO ARENAS E PEDRO JUAN GUTIÉRREZ A PARTIR DOS ECOS DA REVOLUÇÃO JOSÉ VERANILDO LOPES DA COSTA JUNIOR THAYS KEYLLA DE ALBUQUERQUE}

A água foi amolecendo tudo e desabou. $\mathrm{O}$ prédio ficou igual àquelas casinhas de bonecas em que falta uma parede e se vêem os móveis e todo interior. Não parecia real. Houve muita confusão. Os bombeiros tiraram dois cadáveres dos escombros. Mas nos deixaram morando lá. Disseram que o resto do prédio era firme e não tinha perigo. ${ }^{\text {XII }}$

Nesse trecho, Pedro Juan descreve a situação narrativa com as seguintes palavras: "não parecia real". Esse texto nos remete ao relato de tantos estrangeiros que visitavam Havana e tinham a mesma sensação de espanto: não pode ser real. $\mathrm{O}$ espaço provoca a ideia de ruína, vestígio, um lugar perdido no tempo, a sensação que a qualquer momento a cidade poderia desabar. Mais que isso, o assombro sobre: como pode estar de pé? Como ainda pode aguentar? Nesse sentido, mais que espaço, Havana também pode ser considerada personagem com aspectos bem específicos em corpo físico e personalidade, com características marcadas, paradoxalmente, pelo deterioro e a resistência.

Em outro conto/capítulo, intitulado "Solitário, resistindo", Pedro Juan conta sobre um espaço que aparece constante em vários momentos do livro: o banheiro. Ao descrever a situação no cortiço, percebemos como a conjuntura social em Cuba subverte os limites entre o pessoal e o coletivo, a própria concepção de um local reservado e íntimo se dissolve:

Fui para o meu quarto no terraço. Em Centro Havana. É um bom lugar. O problema lá são os vizinhos e o banheiro coletivo. O banheiro mais nojento do mundo, compartilhado por cinquenta moradores, que se multiplicam, porque a maioria é do Leste. Vêm para Havana aos bandos, fugindo da miséria. Em Guantánamo você entra para polícia e logo depois consegue transferência para Havana (em Havana ninguém quer ser policial) e leva junto a família inteira. E se viram para morar todos num quarto de quatro metros por quatro. Não sei como. Mas conseguem. E no banheiro a merda chega até o teto. Nesse banheiro cagam, mijam e tomam banho diariamente nada menos que duzentas pessoas. Sempre tem fila. Mesmo que você esteja se cagando, tem que entrar na fila. Muita gente, eu entre eles, nunca entra na fila: cago num papel e jogo o pacote de merda no terraço do edifício ao lado, que é mais baixo. Ou na rua. Tanto faz. Um desastre! Mas é assim mesmo. A gente às vezes está em baixa e tem que se acostumar. ${ }^{\text {XXIII }}$

A atmosfera de precariedade se desenvolve no decorrer do livro, o cheiro de merda perpassa toda a narrativa, a imagem do banheiro e dos edifícios em ruínas também. Explora-se mais uma vez a ideia do absurdo, do incoerente: "Não sei como. Mas conseguem". Vez ou outra aparece o malecón como um intervalo, um tempo de respiro entre os episódios de merda. Pedro Juan está permanentemente buscando e mudando de trabalhos, legais e ilegais (se envolve com tráfico de comida e obras de arte, por exemplo), se envolve em diferentes histórias amorosas (demonstra naturalidade em ter uma companheira que o sustenta com prostituição), mas apesar da degradação de Cuba ele permanece lá, paradoxalmente, vendo o anseio daqueles que se esforçam para sair da ilha, enquanto ele continua na luta pela sobrevivência, a cada dia, sem desejo de imigrar.

As imagens sobre a Cuba explorada turisticamente e a Cuba conhecida profundamente também aparecem em diversos momentos da obra. Ainda em "Solitário, resistindo", ele volta a falar do espaço onde vive e descreve o edifício a partir da ideia 


\title{
RUÍNAS E MEMÓRIAS DE CUBA: LEITURAS DE REINALDO ARENAS E PEDRO JUAN GUTIÉRREZ A PARTIR DOS ECOS DA REVOLUÇÃO \\ JOSÉ VERANILDO LOPES DA COSTA JUNIOR \\ THAYS KEYLLA DE ALBUQUERQUE
}

de aparência superficial (a capa) versus o conteúdo (o que se encontra dentro), ou seja, o que se vê por fora é bem diferente da experiência das pessoas que vivem dentro, que moram no lugar. O narrador-protagonista Pedro Juan Gutiérrez diz:

\begin{abstract}
Desci as escadas. O edifício é de 1936 e nos seus bons tempos imitava aqueles monstros de Boston e da Filadélfia com fachadas de bancos sólidos e eficazes. Na verdade conserva a fachada, e os turistas se assombram e tiram fotos e o prédio até aparece nas revistas, fotografado geralmente em dias de temporal. Vi fotos alucinantes, com o mar furioso saltando sobre o malecón, com a luz cinza-azulada dos ciclones, e o edifício salpicado de água, mas sólido e antigo. Um castelo majestoso e esplêndido no meio do furacão. Só que por dentro está caindo aos pedaços e é um incrível labirinto de pedaços de escadas sem corrimão, escuro, com cheiro de ranço e de baratas e de merda fresca. E quartos acrescentados, tirando espaço dos corredores, e brigas e gritarias dos negros. Cheguei na calçada e lá em frente vi o letreiro velhíssimo, já quase ilegível: "Uma revolução sem perigo não é revolução. E um revolucionário sem capacidade de assumir o risco não tem decoro". A frase não estava assinada. Pela pinta devia ser do Fidel ou do Raúl. Na esquina tinha um cartaz novo e enorme. Em letras bem grandes, de cores brilhantes dizia: 'Cuba, um país de homens de altura'. Num canto, um atleta negro saltava sobre um céu azul. Sei lá. Era incompreensível. ${ }^{\text {XIV }}$
\end{abstract}

Nesse conto/capítulo que se passa em 1994, há contradições entre o que se vê por fora do edifício, a exuberância da fachada, com a situação interna, labiríntica e fétida. No implícito, podemos nos questionar se de alguma forma, nessa deformação do espaço, que desmorona de um lado, em fragmentos, mas também recebe remendos (puxadinhos) por outros lados, se nessa apresentação espacial, rasgada por camadas de tempo, pelas citações dos jargões revolucionários tão comuns nas ruas e prédios de Havana, não remete também à situação histórica de Cuba, lugar mítico para América Latina, que ainda mantém os ares utópicos da revolução popular, ao mesmo tempo que internamente a população cubana se encontrava perdida e faminta durante a crise dos anos noventa.

Obviamente, o retrato de Cuba feito por Pedro Juan escolhe um ângulo, uma visão crua e desencantada que pode não ser apreciada, inclusive pelos próprios cubanos. Até 2017 o livro não tinha sido publicado em Cuba, só vinte anos depois de seu lançamento na Espanha os cubanos puderam ler uma das obras mais representativas da literatura contemporânea latino-americana, de um dos escritores mais respeitados de sua geração. A memória sobre o passado recente do país, os inúmeros problemas sociais, as consequências do regime revolucionário no presente aparecem tanto nos cochichos dos personagens e nas entrelinhas do livro, quanto na expressividade do autor Pedro Juan Gutierréz na elaboração da própria obra literária. Gutiérrez afirma que não gosta de leituras políticas de sua obra, o que nos parece irônico, já que em Cuba, mais que em qualquer outra parte do mundo, tudo é político.

\section{Considerações finais}




\title{
RUÍNAS E MEMÓRIAS DE CUBA: LEITURAS DE REINALDO ARENAS E PEDRO JUAN GUTIÉRREZ A PARTIR DOS ECOS DA REVOLUÇÃO \\ JOSÉ VERANILDO LOPES DA COSTA JUNIOR \\ THAYS KEYLLA DE ALBUQUERQUE
}

Nesta aproximação às obras de Reinaldo Arenas e Pedro Juan Gutiérrez, compreendemos a literatura como um caminho de reflexão sobre as memórias do passado recente de Cuba e da América Latina. Seguindo esta linha de raciocínio, o texto literário estabelece um diálogo interdisciplinar com outras áreas do saber, como a História. Para Eurídice Figueiredo, no livro A Literatura como arquivo da ditadura brasileira $^{X X V}$, a literatura pode funcionar como um arquivo historiográfico, que nos permite acessar as memórias traumáticas de uma coletividade, no sentido de um arquivo complementar, pois oferece às leitoras e leitores uma possibilidade de leitura mais palpável de experienciar quando comparada aos documentos oficiais. Além disso, esse arquivo permite um olhar diferenciado sobre o passado:

\begin{abstract}
Derrida, ao considerar a lógica e a semântica do arquivo, verifica a existência de uma infinidade de camadas que são superpostas, superimpressas e envolvidas umas nas outras (DERRIDA, 2001, p. 35). Diante disto, o escritor deve trabalhar a partir desses vestígios do passado. Como se trata de uma história rasurada, a recuperação do passado pela escrita (literária, jornalística ou mesmo historiográfica) vai juntar e rearrumar os dados do passado. Podese conceber esta sobreimpressão de elementos como um palimpsesto a ser decifrado, a ser recomposto, ressignificado. ${ }^{X V I}$
\end{abstract}

Nesta perspectiva, os textos de Reinaldo Arenas e Pedro Juan Gutiérrez também funcionam como um arquivo complementar que contam parte da narrativa sobre a revolução popular em Cuba e o espectro da vida pública e privada durante algumas décadas do século XX. Estes dois autores possuem pontos de semelhança e de diferença no projeto literário desenvolvido por cada um deles. Ao tratar especificamente das obras analisadas nesse artigo, notamos duas perspectivas narrativas: Reinaldo Arenas se ocupa de construir uma autobiografia - a qual exprime o seu olhar sobre a sua própria vida em Cuba. Seu texto, escrito em primeira pessoa, provoca um cruzamento entre a sua vida particular e eventos políticos que ocorriam na ilha nos anos 1990. Pedro Juan Gutiérrez também narra em sua obra elementos da vida pública cubana, atrelado às suas vivências pessoais, mas desta vez, a partir de uma perspectiva autoficcional - marcada pela localização dos seus textos nos limites pantanosos entre a realidade e a ficção.

O que propusemos foi uma leitura das suas obras que nos permite refletir sobre alguns desdobramentos da revolução popular cubana a partir do ângulo de dois escritores. Nesse sentido, podemos observar a literatura como ferramenta para configurar memórias tanto sobre as perseguições aos homossexuais exploradas a partir das memórias pessoais de Arenas, quanto sobre as ruínas de Havana e o deterioro social dos anos 90 a partir da autoficção de Gutiérrez. Ambos explorando visões do regime autoritário de Castro.

Dessa leitura chegamos a duas observações: i) as narrativas de Reinaldo Arenas e Pedro Juan Gutiérrez contam o cotidiano da vida de pessoas comuns, trazendo uma visão pouco estudada quando se trata da revolução cubana: a de pessoas que não estavam diretamente ligadas ao regime revolucionário comandado por Fidel Castro; ii) os dois autores sistematizam um conjunto de críticas à conjuntura político-social cubana, como no caso da perseguição aos homossexuais e à fome sistemática dos anos 1990. Entretanto, não se pode utilizar dessas críticas aos desdobramentos do regime para criar no senso comum uma imagem negativa sobre Cuba. A revolução popular 


\section{RUÍNAS E MEMÓRIAS DE CUBA: LEITURAS DE REINALDO ARENAS E PEDRO JUAN GUTIÉRREZ A PARTIR DOS ECOS DA REVOLUÇÃO \\ JOSÉ VERANILDO LOPES DA COSTA JUNIOR \\ THAYS KEYLLA DE ALBUQUERQUE}

contou com amplo apoio da sociedade e significou (como significa até hoje) uma resposta aos mecanismos de poder dos Estados Unidos.

Como podemos notar, através da literatura, há ainda muitas visões para serem exploradas, estudadas e ressignificadas no concernente às memórias e às consequências da revolução cubana, como ela reverberou nas décadas precedentes para as mais diferentes camadas e perfis sociais, e como ela continua a ecoar no presente seja como fantasma reativando medos, seja como farol guiando a utopia da revolução popular latino-americana.

\section{Notas}

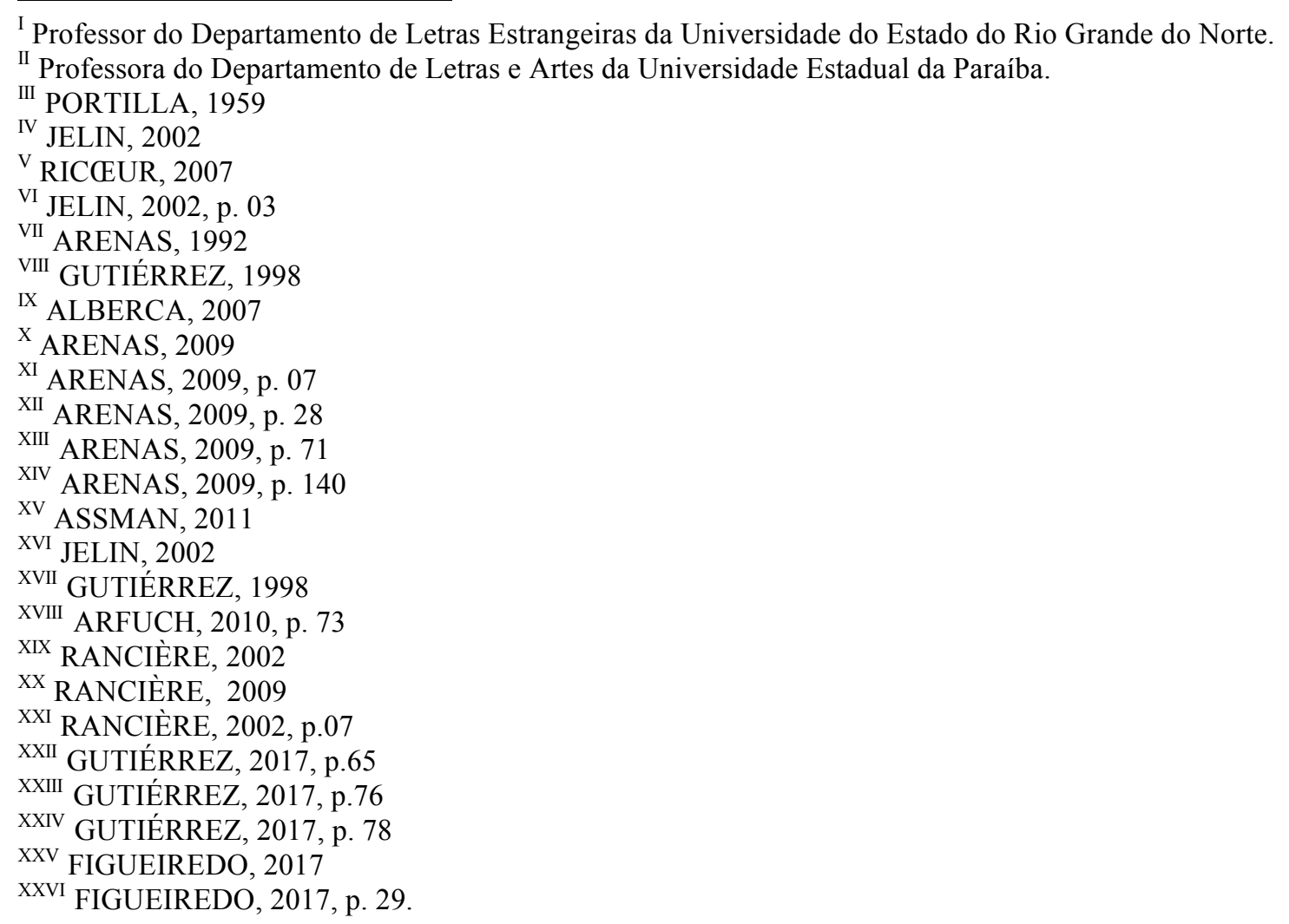

\section{Referências}

ALBERCA, Manuel. El pacto ambiguo: de la novela autobiográfica a la autoficción. Madrid: Biblioteca nueva, 2007.

ARENAS, Reinaldo. Antes que anoiteça. Tradução de Irêne Cubric. Rio de Janeiro BestBolso, 2009.

ARFUCH, Leonor. O Espaço Biográfico: dilemas da subjetividade contemporânea. Tradução Paloma Vidal. Rio de Janeiro: EdUERJ, 2010. 


\section{RUÍNAS E MEMÓRIAS DE CUBA: LEITURAS DE REINALDO ARENAS E PEDRO JUAN GUTIÉRREZ A PARTIR DOS ECOS DA REVOLUÇÃO \\ JOSÉ VERANILDO LOPES DA COSTA JUNIOR \\ THAYS KEYLLA DE ALBUQUERQUE}

ASSMANN, Aleida. Espaços da Recordação: formas e transformações da memória cultural. Tradução de Paulo Soethe. Campinas: Editora da Unicamp, 2011.

FIGUEIREDO, Eurídice. A Literatura como arquivo da ditadura brasileira. Rio de Janeiro: 7 Letras, 2017.

GUTIÉRREZ, Pedro Juan. Trilogia Suja de Havana. Rio de Janeiro: Alfaguarra, 2017.

JELIN, Elizabeth. Los trabajos de la memoria. Madrid: Siglo Veintinuno Editores, 2002.

PORTILLA, Miguel León. Visión de los vencidos. Ciudad de Mexico: UNAM, 1959.

RANCIÈRE, Jacques. A Partilha do sensível: estética e política. Tradução de Mônica Costa Netto. São Paulo: Editora 34, 2009.

A revolução estética e seus resultados. Tradução de Flávia Ragazzo do artigo The Aesthetic Revolution and its Outcomes. New Left Review, NLR 14, p. 133-15. mar./abr. 2002. Disponível em: https://bibliotecadafilo.files.wordpress.com/2013/10/arevoluc3a7c3a3o-estc3a9tica.pdf. Acesso em: 20 abr. 2017.

RICOUER, Paul. A memória, a história, o esquecimento. Tradução de Alain François et.al. Campinas: Editora da UNICAMP, 2007. 